\title{
The degradation behavior of silk fibroin derived from different ionic liquid solvents
}

\author{
Renchuan You ${ }^{1}$, Ying Zhang ${ }^{2}$, Yu Liu ${ }^{1}$, Guiyang Liu ${ }^{1,3}$, Mingzhong Li $^{1 \#}$ \\ ${ }^{1}$ National Engineering Laboratory for Modern Silk, College of Textile and Clothing Engineering, Soochow University, Suzhou, \\ China; ${ }^{\#}$ Corresponding Author: mzli@, suda.edu.cn \\ ${ }^{2}$ College of Chemistry, Chemical Engineering and Materials Science, Soochow University, Suzhou, China \\ ${ }^{3}$ Department of Textile, Nantong Textile Vocational Technology College, Nantong, China
}

Received 25 April 2013; revised 26 May 2013; accepted 4 June 2013

Copyright (C) 2013 Renchuan You et al. This is an open access article distributed under the Creative Commons Attribution License, which permits unrestricted use, distribution, and reproduction in any medium, provided the original work is properly cited.

\section{ABSTRACT}

Establishing an appropriate degradation rate is critical for tissue engineering scaffolds. In this study, the degradation rate of silk fibroin threedimensional scaffolds was regulated by changing the molecular weight (MW) of the silk fibroin. The solubility of silk fibroin depends primarily on the ionic ability of the slovent to dissolve silk fibroin, therefore, we regulated the $\mathrm{MW}$ of the silk fibroin using $\mathrm{LiBr}, \mathrm{Ca}\left(\mathrm{NO}_{3}\right)_{2}$ and $\mathrm{CaCl}_{2}$ to dissolve the silk fibers. SDS-PAGE analysis showed that the $\mathrm{MW}$ of the $\mathrm{CaCl}_{2}$-derived silk fibroin was lower than the MW produced using $\mathrm{LiBr}$ and $\mathrm{Ca}\left(\mathrm{NO}_{3}\right)_{2}$. In vitro and in vivo degradation results showed that the scaffolds prepared by low-MW silk fibroin were more rapidly degraded. Furthermore, FTIR and amino acid analysis suggested that the amorphous regions were preferentially degraded by Collagenase IA, while the SDS-PAGE and amino acid analysis indicated that the scaffolds were degraded into polypeptides (mainly at $10-30 \mathrm{kDa}$ ) and amino acids. Because the $\mathrm{CaCl}_{2}$-derived scaffolds contained abundant low MW polypeptides, inter-intramolecular entanglement and traversing of molecular chains in the crystallites reduced, which resulted in rapid degradation. The in vivo degradation results suggested that the degradation rate of the $\mathrm{CaCl}_{2}$ derived scaffolds was better matched to dermis regeneration, indicating that the degradation rate of silk fibroin can be effectively regulated by

\footnotetext{
*This work was supported by the College Natural Science Research Project of Jiangsu Province (12KJA430003), the National Nature Science Foundation of China (30970714), the Key Laboratory Opening Program of Jiangsu Higher Education Institutions (KJS1216) and the Priority Academic Program Development of Jiangsu Higher Education Institutions.
}

changing the MW to achieve a suitable dermal tissue regeneration rate.

Keywords: Silk Fibroin; Molecular Weight; Scaffolds; Degradation; Skin Tissue Engineering

\section{INTRODUCTION}

The degradation rates of tissue engineering scaffolds and drug carriers should either mirror the rate of new tissue formation or be adequate for the controlled release of bioactive molecules [1]. Silk fibroin (SF) has been exploited as a biomaterial for use in bone, vessel, nerve, cartilage and meniscus tissue engineering scaffolds [2-6] because of its outstanding mechanical properties as well as its biocompatibility and its versatile processability into many material formats [6]. Hence, for biomedical applications, it is essential to investigate the biodegradation behavior of SF materials.

The degradability of silk biomaterials is related to the type of enzyme experienced during exposure, the content of $\beta$-sheet crystallinity, morphological features and the mode of processing [7-12]. Several proteolytic enzymes, such as protease XIV, Collagenase IA and $\alpha$-chymotrypsin, have been used to digest natural SF fibers, films, nanofibers, conduits and porous scaffolds [7-11,13-14]. Protease XIV was found to be more aggressive than $\alpha$-chymotrypsin and collagenase IA [7], while $\alpha$-chymotrypsin can digest the less crystalline regions of the SF but does not degrade the $\beta$-sheet crystals [15]. However, the $\beta$-sheet silk crystals can be degraded into nanofibrils and then into nanofilaments as well as soluble silk fragments by protease XIV [15]. Natural SF fibers consisting of abundant $\beta$-sheet sturcture can also be degraded by protease XIV, yielding a mass loss greater than $50 \%$ after 42 days [8]. Due to the stability of $\beta$-sheet silk crystals against enzymatic degradation $[9,11,15]$, thus the degra- 
dation rate of SF materials can be adjusted by changing $\beta$-sheet content [9]. For various biomedical applications, natural SF fibers must be regenerated and processed into different products, such as nanofibers, films or threedimensional (3D) scaffolds. After regeneration, fabrication and post-treatment, the changes in the pore size, porosity and crystallinity cause variation in the degradation rate. Consequently, the enzymatic degradation of regenerated SF materials was more repid than the degradation of natural SF fibers $[10,11]$. Further, long-term in vivo degradation also demonstrated that the degradation behavior of the $3 \mathrm{D} \mathrm{SF}$ scaffolds is related to the fabrication methods (where the scaffolds are derived from either all-aqueous or organic solvents), and different pore structures resulted from the different preparation processes [12]. However, the desired scaffold degradation rate depends on the specific tissue engineering application; for example, a scaffold for bone tissue formation requirs a slow degradation rate, while rapid degradation is required for dermal tissue repair. Thus far, changing the morphologies and crystal structures of SF scaffolds has not been able to provide the different degradation rates required for the various tissue engineering applications.

The degradation rate of polymers was also significantly influenced by the chemical composition and molecular weight (MW) of the polymer [16,17]. The solubility of natural SF fibers in ionic liquids depends on the ability of both the cation and anion to disrupt the hydrogen bonding in the silk crystal [18]; therefore, the MW level of regenerated SF can be regulated by dissolution methods. The aim of this study was to investigate the relationship between MW and the SF degradation for regulating the degradation rate of 3D scaffolds. First, SF solutions with various molecular weight distributions (MWDs) were obtained by using $\mathrm{LiBr}, \mathrm{Ca}\left(\mathrm{NO}_{3}\right)_{2}$ and $\mathrm{CaCl}_{2}$ to dissolve natural SF fibers; the SF solutions derived from the three ionic liquids were lyophilized to prepare the 3D scaffolds. Subsequently, the in vitro degradation was conducted for 18 days in a physiological model using Collagenase IA. Further, the scaffolds were implanted into the skin defects in Sprague-Dawley (SD) rats for 28 days to study the relationship between the MW level and in vivo degradation.

\section{MATERIALS AND METHODS}

\subsection{Preparation of the Regenerated SF and 3D Scaffolds}

Bombyx mori raw silk fibers (Huzhou, China) were degummed three times in $0.05 \mathrm{wt} \% \mathrm{Na}_{2} \mathrm{CO}_{3}$ at $98^{\circ} \mathrm{C}$ $100^{\circ} \mathrm{C}$ for $30 \mathrm{~min}$, and then dried in an oven after rinsing. The extracted SF fibers were dissolved in $9.3 \mathrm{M} \mathrm{LiBr}$ at $60^{\circ} \mathrm{C} \pm 2^{\circ} \mathrm{C}$ for $2 \mathrm{~h}, \mathrm{Ca}\left(\mathrm{NO}_{3}\right)_{2}$ at $100^{\circ} \mathrm{C} \pm 2^{\circ} \mathrm{C}$ for $3 \mathrm{~h}$ and a ternary solvent of $\mathrm{CaCl}_{2}: \mathrm{CH}_{3} \mathrm{CH}_{2} \mathrm{OH}: \mathrm{H}_{2} \mathrm{O}(1: 2: 8$ molar ratio) at $72^{\circ} \mathrm{C} \pm 2^{\circ} \mathrm{C}$ for $1 \mathrm{~h}$; the resulting dissolution products were dialyzed (MWCO 9000), respectively, in deionized water for 4 days. The SF solutions were obtained after filtration and then stored at $4^{\circ} \mathrm{C}$. The SF solutions derived from the three ionic liquids were diluted to $2 \%$; then, 2-morpholinoethanesulfonic acid (MES), NHydroxysuccinimide (NHS) and 1-ethyl-3-(3-dimethylaminopropyl) carbodiimide hydrochloride (EDC) (all obtained from Sigma-Aldrich) were added to the SF solutions at $20 \%, 10 \%$ and $20 \%$ of the SF weight, respectively. The mixtures were poured into stainless steel vesseles and frozen at $-40^{\circ} \mathrm{C}$ for $6 \mathrm{~h}$, followed by lyophilization for $48 \mathrm{~h}$ using a Virtis Genesis 25-LE Freeze Dryer.

\subsection{In Vitro Degradation}

Collagenase IA (from Clostridium histolyticum, EC 3.4.24.3, Sigma-Aldrich, was dissolved in phosphatebuffered saline (PBS, $0.05 \mathrm{M}, \mathrm{pH} 7.4$ ) at $1.0 \mathrm{U} / \mathrm{ml}$. The scaffolds were cut into squares $(3 \times 3 \mathrm{~cm}, \mathrm{n}=3$ per time point) and weighted. The samples were incubated in $5 \mathrm{ml}$ of enzyme solution for $1,3,6,12$ and 18 days at $37^{\circ} \mathrm{C}$ under slow shaking, and in PBS under otherwise identical conditions as a control. The degradation products and remains were collected for analysis at 1, 3, 6, 12 and 18 days, and the degradation solution was replaced with a fresh enzyme solution every 3 days. The samples at each time point were rinsed with deionized water and then lyophilized. Quantitative changes were expressed as the percentage of weight retained relative to the initial dry weight.

\subsection{The Morphological and Conformational Change in the Scaffolds}

After enzymatic degradation, the scaffolds were lyophilized and examined by scanning electron microscopy (SEM, S-570, Hitachi, Japan). For the molecular conformation measurements, Fourier-transform infrared spectroscopy (FTIR) analysis was performed using a Nicolet 5700 spectrometer (Thermo Scientific, USA). The infrared spectra were analyzed in the amide I region (1595 $1705 \mathrm{~cm}^{-1}$ ) using Opus 6.5 software (Bruker, Germany). Deconvolution was performed using a Lorentzian line shape with a half-bandwidth of $25 \mathrm{~cm}^{-1}$ and a noise reduction factor of 0.3 . The FTIR spectra were curve-fitted to measure the relative areas of the amide I region components $[4,19]$.

\subsection{Sodium Dodecyl Sulfate-Polyacrylamide Gel Electrophoresis (SDS-PAGE)}

The samples were run on a $5 \%-15 \%$ polyacrylamide gel in running buffer $(0.25 \mathrm{M}$ Tris- $\mathrm{HCl}, 10 \% \mathrm{SDS}, 0.5 \%$ bromophenol blue, 50\% glycerol and 5\% 2-mercaptoethanol, $\mathrm{pH} 8.3$ ). The stacking gel contained 5\% acryla- 
mide, $0.1 \%$ ammonium persulfate and $0.1 \%$ SDS in 1.0 $\mathrm{M}$ Tris- $\mathrm{HCl}$ buffer ( $\mathrm{pH} 6.8$ ), and the gradient separating gel contained 8 to $15 \%$ acrylamide, $0.1 \%$ ammonium persulfate and $0.1 \%$ SDS in $1.5 \mathrm{M}$ Tris- $\mathrm{HCl}$ buffer $(\mathrm{pH}$ 8.8). Pre-stained protein served as the MW markers (25 200 and $43-300 \mathrm{kDa}$ ) for examining the SF MWD values; the gels were stained with a Easy Stain Coomassie Blue Kit (Invitrogen, Carlsbad, CA). The degradation products were examined to analyze the polypeptides released during degradation. The MW markers were 10 $200,10-100$ and $10-50 \mathrm{kDa}$ for the degradation products at $3 \mathrm{~d}, 6 \mathrm{~d}$ and $18 \mathrm{~d}$, respectively.

\subsection{Amino Acid Analysis}

For the free amino acids determination of the degradation products, the $5 \mathrm{ml}$ of $8 \%$ sulfosalicylic acid solution was added to an equal volume of the degradation solution and centrifuged at 15,000 rpm for $15 \mathrm{~min}$ to remove the protein. The collected supernatant was diluted with $0.02 \mathrm{~N} \mathrm{HCl}$ and filtered with Millipore $0.22-\mu \mathrm{m}$ syringe filters (Milford, USA) [11]. A $20 \mathrm{~mL}$ filtrate was analyzed using an amino acid analyzer (L-8800, Hitachi, Japan).

To measure the amino acids contents of the samples remaining after degradation, the samples were hydrolyzed in $6 \mathrm{~N} \mathrm{HCl}$ at $110^{\circ} \mathrm{C}$ for $24 \mathrm{~h}$ and then analyzed using an amino acid analyzer.

\subsection{In Vivo Degradation}

The SF scaffolds $(20 \times 20 \mathrm{~mm})$ were implanted into the skin defects in the back of SD rats $(180 \mathrm{~g}-200 \mathrm{~g}$, SPF grade, male) with 5 rats in each group. Pentobarbital sodium (30 mg/kg body weight) was administered presurgically. Full-thickness wounds (approximately $20 \mathrm{~mm}$ $\times 20 \mathrm{~mm}$ ) were created on the upper back of each rat, and the scaffolds were implanted as dermal substitutes into the defect sites, followed by covering with thin split-thickness skin grafts. The wounds were then closed with 6-0 silk sutures and covered by Vaseline carbasus and dry carbasus. Finally, the wounds were treated with circular bandages. The Specimens were harvested at 28 days and fixed in 4\% formaldehyde in PBS at room temperature before embedding in paraffin. The sections were stained with hematoxylin and eosin ( $\mathrm{H} \& \mathrm{E})$ and were observed under an optical microscope (Olympus BH-2, Japan). The H \& E images were used to assess the remaining area of each scaffold. The scaffold degradation ratio was calculated using SigmaScan Pro5.0 software (IBM, USA) according to a previously reported method [20]. All animal experiments were in accordance with the Management Ordinance of Experimental Animal of China ([2001] No. 545) and were approved by the Jiangsu Province in experimental animals management rules ([2008] No. 26).

\section{RESULTS}

\subsection{MWD of the Silk Fibroin}

The silk fibroin consists of 6 heavy chains $(\sim 390 \mathrm{kDa})$, 6 light chains $(\sim 26 \mathrm{kDa})$ and a P25 chain $(\sim 25 \mathrm{kDa})$ [21-23]. As shown in Figure 1, the SDS-PAGE analysis indicated that the SF solutions produced by the different solvents all have sequential bands from about 20 to 300 $\mathrm{kDa}$, indicating that the SF has been partially degraded and hydrolyzed into a mixture of polypeptides with various MWs. The $\mathrm{CaCl}_{2}$-derived SF solution has a lower MW level (under $72 \mathrm{kDa}$ ), that is, at 35 - $72 \mathrm{kDa}$ (Figure 1(b)). The MWDs of the SF samples derived from the $\mathrm{LiBr}$ and $\mathrm{Ca}\left(\mathrm{NO}_{3}\right)_{2}$ were similar in the low-MW region, but the band of the LiBr-derived SF was stronger than the band for $\mathrm{Ca}\left(\mathrm{NO}_{3}\right)_{2}$ over $300 \mathrm{kDa}$ (Figures 1(a) and (c)). This result sugguests that $\mathrm{LiBr}$ is mild with respect to the degradation of $\mathrm{SF}$, while the $\mathrm{CaCl}_{2}$ ionic liquid exhibits the strongest degradation behavior. In this study, the MW levels derived from the three solvents were, in descending order, $\mathrm{LiBr}>\mathrm{Ca}\left(\mathrm{NO}_{3}\right)_{2}>\mathrm{CaCl}_{2}$.

\subsection{Morphological Observations}

As shown in Figures 2(a-0), (b-0) and (c-0)), the SF scaffolds derived from the three solvents exhibit porous morphologies, where the pore shapes are irregular polygons and fusiform. The pore wall thicknesses of the three scaffolds are similar. The large pores have a long diameters in the range of approximately $100-600 \mu \mathrm{m}$ and short diameters of approximately $50-200 \mu \mathrm{m}$, while the long diameters and short diameters were both approxi-

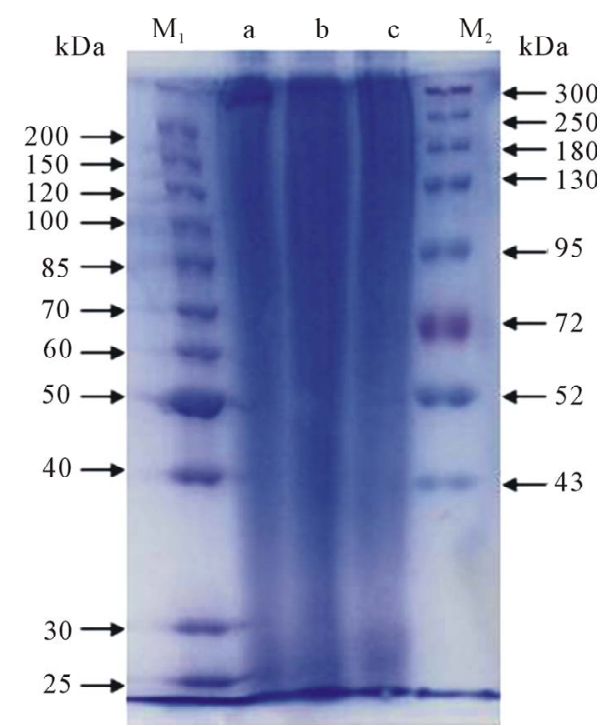

Figure 1. The SDS-PAGE of the silk fibroin from (a) $\mathrm{LiBr}$; (b) $\mathrm{CaCl}_{2}$; (c) $\mathrm{Ca}\left(\mathrm{NO}_{3}\right)_{2}$, where $\left(\mathrm{M}_{1}\right)$ and $\left(\mathrm{M}_{2}\right)$ are the molecular weight markers. The concentration of the separating gel was $8 \%$. 


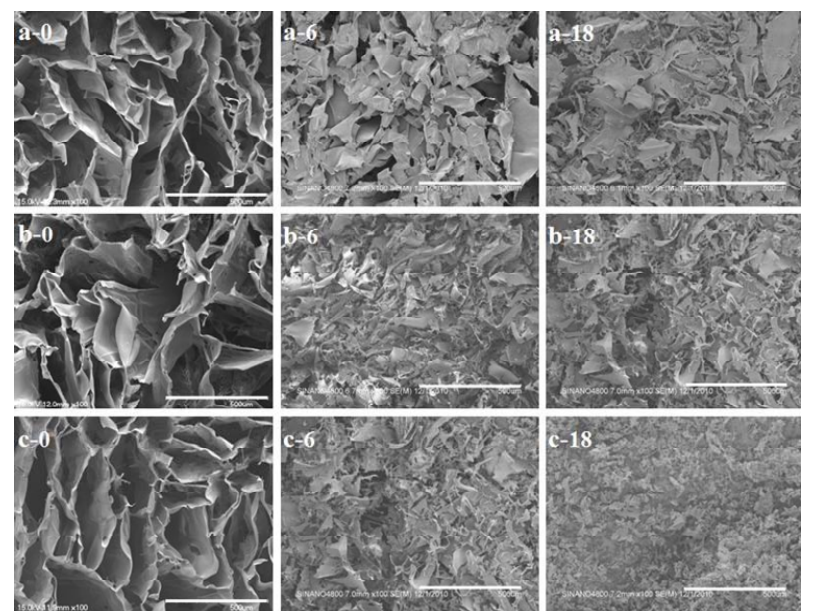

Figure 2. SEM images of the scaffolds incubated in the enzyme solution for 0,6 and 18 days: (a) The LiBr-derived scaffold; (b) The $\mathrm{Ca}\left(\mathrm{NO}_{3}\right)_{2}$-derived scaffold; (c) The $\mathrm{CaCl}_{2}$-derived scaffold. Scale bars $=500 \mu \mathrm{m}$.

mately $10-100 \mu \mathrm{m}$ for the small pores. The average pore diameters of the three scaffolds were similar.

The scaffolds began to collapse after 6 days of incubation, however, partial scaffold integrity was maintained. For example, a shrunken pore structure could still be observed in the LiBr-derived scaffold (Figures 2(a-6), (b-6) and (c-6)). With further degradation, all of the scaffolds were unable to maintain integrity and collapsed. The residual $\mathrm{CaCl}_{2}$-derived scaffold was powder-like, but the remains of the $\mathrm{LiBr}$-derived scaffold and $\mathrm{Ca}\left(\mathrm{NO}_{3}\right)_{2}$-derived scaffold were still sheet-like (Figures 2(a-18), (b-18) and (c-18)). This result indicates that the LiBr-derived scaffold and $\mathrm{Ca}\left(\mathrm{NO}_{3}\right)_{2}$-derived scaffold were able to maintain the structural integrity for longer times, while the $\mathrm{CaCl}_{2}$-derived scaffold was more susceptible to enzymatic degradation.

\subsection{Mass Loss}

Figure 3 showed that the mass loss of the SF scaffolds increased with the enzymatic degradation time. After 3 days, the residual weights of the scaffolds derived from $\mathrm{LiBr}, \mathrm{Ca}\left(\mathrm{NO}_{3}\right)_{2}$ and $\mathrm{CaCl}_{2}$ were $90.33 \%, 88.29 \%$ and $85.68 \%$, respectively. Following further degradation, the difference of residual weights among the three scaffolds significantly increased, yielding residual weights of $81.92 \%, 79.38 \%$ and $66.25 \%$ at 6 days and $46.33 \%$, $44.12 \%$ and $26.25 \%$ at 12 days. At 18 days, the residual weight of the $\mathrm{CaCl}_{2}$-derived scaffolds was only $6.34 \%$, showing the most rapid degradation rate in comparison to the $\mathrm{LiBr}$ and $\mathrm{Ca}\left(\mathrm{NO}_{3}\right)_{2}$-derived scaffolds. The mass loss data were fitted with linear trendlines, giving linearly dependent coefficients of a, b and c (Figure 3) valued at $0.9827,0.9872$ and 0.9874 , respectively. These results indicate that the mass loss trend was approxi-

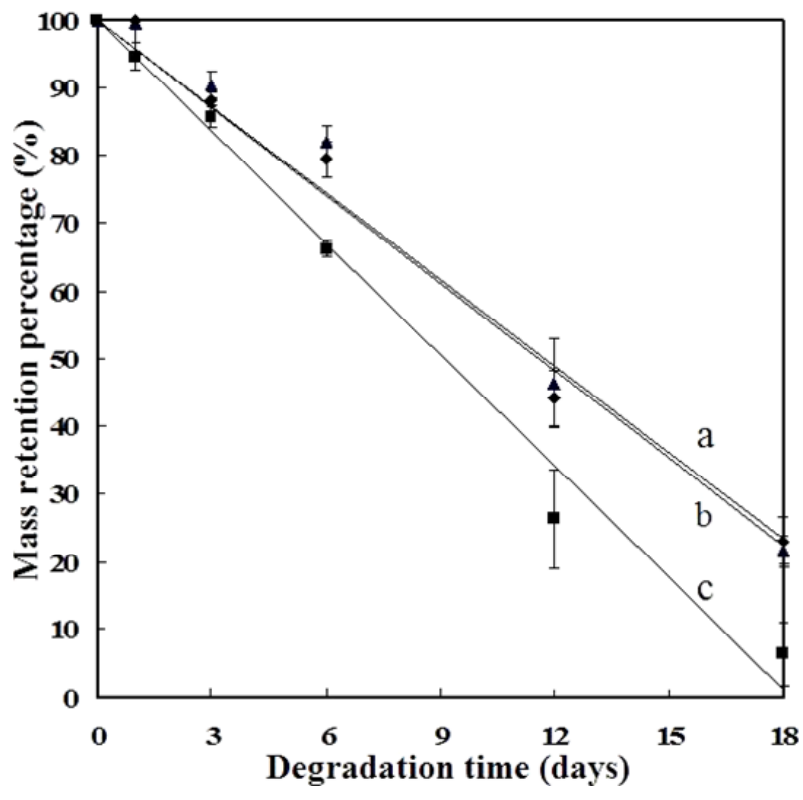

Figure 3. Quantitative changes in the SF scaffolds during degradation: $(\boldsymbol{\Delta})$ the $\mathrm{LiBr}$-derived scaffolds, $(\bullet)$ the $\mathrm{Ca}\left(\mathrm{NO}_{3}\right)_{2}-$ derived scaffolds, ( $\mathbf{\square})$ the $\mathrm{CaCl}_{2}$-derived scaffolds. The labels a, $\mathrm{b}$ and $\mathrm{c}$ represent the linear trendlines for the degradation dates from the $\mathrm{LiBr}, \mathrm{Ca}\left(\mathrm{NO}_{3}\right)_{2}$ and $\mathrm{CaCl}_{2}$-derived scaffolds, respectively.

mately linear. The slopes of the three straight lines show the different degradation rates, while the in vitro degradation data suggest that the enzymatic degradation rate was, in descending order, $\mathrm{CaCl}_{2}$-derived scaffolds > $\mathrm{Ca}\left(\mathrm{NO}_{3}\right)_{2}$-derived scaffolds $>\mathrm{LiBr}$-derived scaffolds.

\subsection{Conformational Changes during in Vitro Degradation}

The FTIR spectra were used to examine the conformational changes in the SF scaffolds during degradation. The absorption peaks of the scaffolds at $1651 \mathrm{~cm}^{-1}$ (amide I) and $1540 \mathrm{~cm}^{-1}$ (amide II) were observed (Figures 4(a-0), (b-0) and (c-0)) before degradation, and the absorption peaks at $1524 \mathrm{~cm}^{-1}$ (amide II), representing the $\beta$-sheet structure, were very weak. This result indicates that the secondary structures of the scaffolds were mainly random coil and $\alpha$-helix before degradation. After degradation for 6 days, the absorption peaks at $1651 \mathrm{~cm}^{-1}$ (amide I) and $1540 \mathrm{~cm}^{-1}$ (amide II) weakened, while the peaks at $1628 \mathrm{~cm}^{-1}$ appeared, representing the characteristic absorption peaks of the $\beta$-sheets (Figures 4(a-6), (b-6) and (c-6)). Following 18 days of degradation, the peaks at $1651 \mathrm{~cm}^{-1}$ and $1540 \mathrm{~cm}^{-1}$ disappeared, while strong peaks at $1628 \mathrm{~cm}^{-1}$ and $1524 \mathrm{~cm}^{-1}$ were observed instead (Figures 4(a-18), (b-18) and (c-18)). This observation indicates that the random coil structure of the SF scaffolds decreased after degradation and that the main conformation was a $\beta$-sheet structure in the residual scaffolds. 


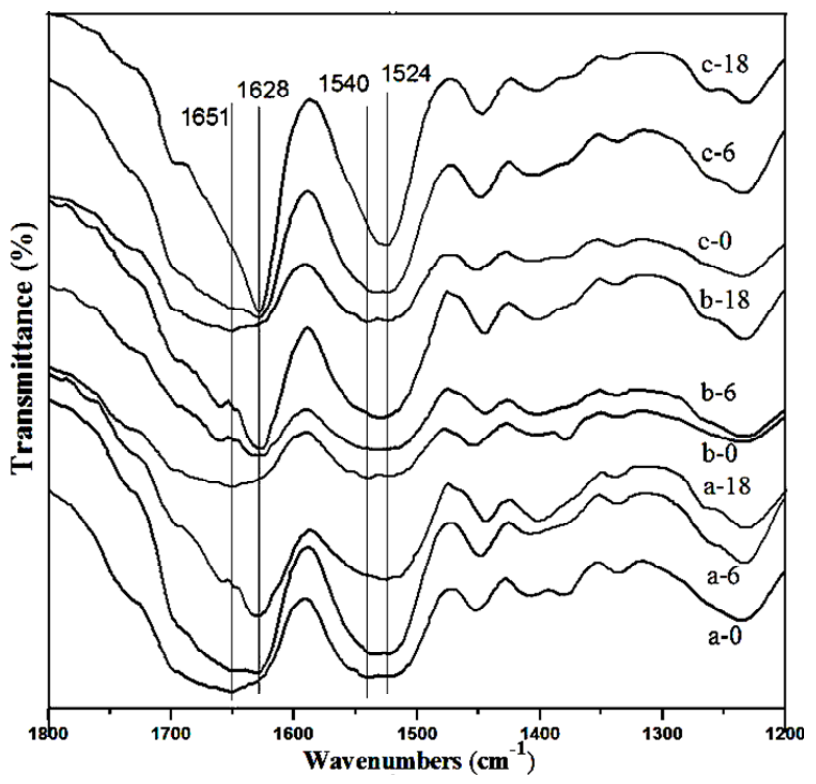

Figure 4. FTIR spectra of (a) The LiBr-derived scaffold; (b) The $\mathrm{Ca}\left(\mathrm{NO}_{3}\right)_{2}$-derived scaffold; (c) The $\mathrm{CaCl}_{2}$-derived scaffold after degradation for $0,6,18$ days.

As shown in Table 1, the result of the fit covering the amide I region $\left(1595-1705 \mathrm{~cm}^{-1}\right)$ shows the contents of the various secondary structures. Before degradation, the $\beta$-sheet contents of the scaffolds derived from $\mathrm{LiBr}$, $\mathrm{Ca}\left(\mathrm{NO}_{3}\right)_{2}$ and $\mathrm{CaCl}_{2}$ were $31.7 \%, 30.7 \%$ and $30.0 \%$, respectively; no significant difference was found. However, the random coil contents of $15.9 \%, 17.4 \%$ and $21.5 \%$ show a significant difference; therefore, the result imply that the SF regeneration process affected both the MW and secondary structures. After 6 days, the $\beta$-sheet con- tents of the scaffolds derived from $\mathrm{LiBr}, \mathrm{Ca}\left(\mathrm{NO}_{3}\right)_{2}$ and $\mathrm{CaCl}_{2}$ increased, respectively, to $35.1 \%, 33.0 \%$ and $36.3 \%$, and the random coil contents decreased to $14.8 \%, 13.7 \%$ and $16.1 \%$. At 18 days, the $\beta$-sheet contents had further increased, respectively, to $36.5 \%, 36.9 \%$ and $43.2 \%$; correspondingly, the random coil contents decreased to $13.8 \%$, $13.1 \%$ and $9.7 \%$. This result indicates that Collagenase IA preferentially attacks amorphous regions, resulting in the increased relative $\beta$-sheet content.

\subsection{MWD of the Degradation Products}

SDS-PAGE analysis was used to examine the degradation products at 3,6 and 18 days (Figure 5). Obvious sequential bands were observed at each degradation stages, suggesting that the SF scaffolds were degraded into polypeptides and then released into the enzyme solutions. Moreover, the bands of the $\mathrm{CaCl}_{2}$-derived scaffolds were stronger in the lower MW regions $(10-30$ $\mathrm{kDa}$ ) (Figure 5). Therefore, the SF scaffolds can be degraded into low-MD polypeptides by Collagenase IA, and the low-MD polypeptides $(10-30 \mathrm{kDa})$ are readily released from the $\mathrm{CaCl}_{2}$-derived scaffolds into enzyme solutions.

\subsection{Amino Acids Analysis of the Degradation Remains and Products}

The amino acid composition of SF from B. mori consists primarily of Gly, Ala and Ser. Tables 2-3 show that the Gly, Ala and Ser contents are approximately $84 \%$ of the total amino acid fraction. After degradation, the contents of Gly, Ala and Ser which mainly existed in crystal-

Table 1. The secondary structure content of the SF scaffolds derived from the deconvoluted amide I regions of the FTIR spectra after degradation for $0,6,18$ days.

\begin{tabular}{|c|c|c|c|c|}
\hline SF scaffold & Conformation & 0 day & 6 days & 18 days \\
\hline \multirow{4}{*}{ LiBr-derived scaffolds } & $\alpha$-helix (\%) & 22.3 & 21.3 & 21.1 \\
\hline & $\beta$-sheet $(\%)$ & 31.7 & 35.1 & 36.5 \\
\hline & Random coil (\%) & 15.9 & 14.8 & 13.8 \\
\hline & Turns (\%) & 26.3 & 23.4 & 19.6 \\
\hline \multirow{4}{*}{$\begin{array}{l}\mathrm{Ca}\left(\mathrm{NO}_{3}\right)_{2} \text {-derived } \\
\text { scaffolds }\end{array}$} & $\alpha$-helix (\%) & 22.0 & 21.7 & 21.3 \\
\hline & $\beta$-sheet $(\%)$ & 30.7 & 33.0 & 36.9 \\
\hline & Random coil (\%) & 17.4 & 13.7 & 13.1 \\
\hline & Turns $(\%)$ & 27.1 & 24.8 & 22.2 \\
\hline \multirow{4}{*}{$\mathrm{CaCl}_{2}$-derived scaffolds } & $\alpha$-helix (\%) & 20.5 & 20.5 & 19.8 \\
\hline & $\beta$-sheet $(\%)$ & 30.0 & 36.3 & 43.2 \\
\hline & Random coil (\%) & 21.5 & 16.1 & 9.7 \\
\hline & Turns (\%) & 23.0 & 21.1 & 20.4 \\
\hline
\end{tabular}


Table 2. The amino acid compositions of the degradation remains and the free amino acid contents of the degradation products from the LiBr-derived scaffold. ND*: Not determined.

\begin{tabular}{|c|c|c|c|c|c|}
\hline \multirow{2}{*}{ Amino acids } & \multicolumn{3}{|c|}{ Amino acid compositions of the remains (mol\%) } & \multicolumn{2}{|c|}{ Free amino acid contents of the degradation products $(\mu \mathrm{g} / \mathrm{mL})$} \\
\hline & 0 day & 6 days & 18 days & 6 days & 18 days \\
\hline Asp & $1.66 \pm 0.01$ & $1.59 \pm 0.00$ & $1.21 \pm 0.01$ & $2.60 \pm 0.08$ & $0.80 \pm 0.01$ \\
\hline Thr & $0.88 \pm 0.01$ & $0.87 \pm 0.01$ & $0.73 \pm 0.01$ & $0.20 \pm 0.03$ & $1.50 \pm 0.28$ \\
\hline Ser & $10.58 \pm 0.01$ & $10.45 \pm 0.01$ & $11.07 \pm 0.03$ & $7.35 \pm 0.13$ & $4.50 \pm 0.28$ \\
\hline Glu & $1.57 \pm 0.01$ & $1.51 \pm 0.01$ & $0.69 \pm 0.01$ & $\mathrm{ND}^{*}$ & $8.05 \pm 1.38$ \\
\hline Gly & $43.29 \pm 0.01$ & $43.48 \pm 0.04$ & $44.70 \pm 0.01$ & $229.80 \pm 0.00$ & $189.25 \pm 0.35$ \\
\hline Ala & $30.23 \pm 0.09$ & $30.10 \pm 0.03$ & $30.86 \pm 0.03$ & $36.90 \pm 0.42$ & $17.95 \pm 0.21$ \\
\hline Cys & $0.01 \pm 0.00$ & $0.04 \pm 0.03$ & $0.45 \pm 0.01$ & $\mathrm{ND}^{*}$ & $12.20 \pm 0.25$ \\
\hline Val & $1.88 \pm 0.01$ & $1.97 \pm 0.01$ & $1.82 \pm 0.01$ & $1.90 \pm 0.00$ & $\mathrm{ND}^{*}$ \\
\hline Met & $\mathrm{ND}^{*}$ & $0.06 \pm 0.01$ & $0.04 \pm 0.01$ & $\mathrm{ND}^{*}$ & $\mathrm{ND}^{*}$ \\
\hline Ile & $0.57 \pm 0.01$ & $0.54 \pm 0.00$ & $0.42 \pm 0.00$ & $\mathrm{ND}^{*}$ & $\mathrm{ND}^{*}$ \\
\hline Leu & $0.36 \pm 0.00$ & $0.34 \pm 0.01$ & $0.20 \pm 0.01$ & $\mathrm{ND}^{*}$ & $\mathrm{ND}^{*}$ \\
\hline Tyr & $4.76 \pm 0.05$ & $4.71 \pm 0.01$ & $4.40 \pm 0.00$ & $10.25 \pm 0.07$ & $3.00 \pm 0.42$ \\
\hline Phe & $0.69 \pm 0.01$ & $0.66 \pm 0.01$ & $0.51 \pm 0.01$ & $11.20 \pm 0.07$ & $10.75 \pm 0.63$ \\
\hline Lys & $0.21 \pm 0.00$ & $0.21 \pm 0.00$ & $0.18 \pm 0.01$ & $0.55 \pm 0.08$ & $0.00 \pm 0.00$ \\
\hline $\mathrm{NH}_{3}$ & $2.48 \pm 0.00$ & $2.26 \pm 0.00$ & $2.17 \pm 0.00$ & $199.15 \pm 1.33$ & $382.05 \pm 0.64$ \\
\hline His & $0.20 \pm 0.00$ & $0.19 \pm 0.01$ & $0.14 \pm 0.01$ & $\mathrm{ND}^{*}$ & $\mathrm{ND}^{*}$ \\
\hline Arg & $0.48 \pm 0.00$ & $0.44 \pm 0.01$ & $0.31 \pm 0.01$ & $\mathrm{ND}^{*}$ & $\mathrm{ND}^{*}$ \\
\hline Pro & $0.17 \pm 0.01$ & $0.17 \pm 0.01$ & $0.11 \pm 0.01$ & $\mathrm{ND}^{*}$ & $\mathrm{ND}^{*}$ \\
\hline Tatol & 100.02 & 100.05 & 100.05 & $499.90 \pm 1.10$ & $630.10 \pm 1.17$ \\
\hline
\end{tabular}

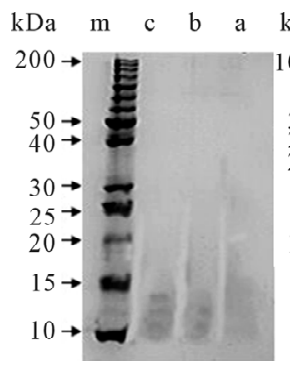

(A)

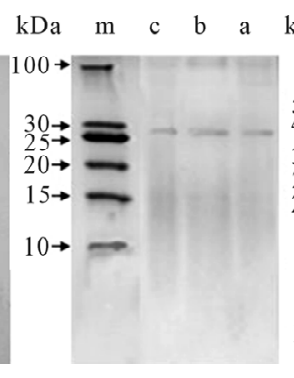

(B)

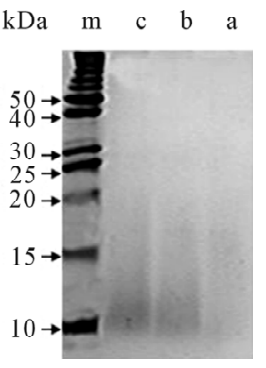

(C)
Figure 5. The SDS-PAGE of the degradation products from: (a) The LiBr-derived scaffolds; (b) The $\mathrm{Ca}\left(\mathrm{NO}_{3}\right)_{2}$-derived scaffolds, (c) the $\mathrm{CaCl}_{2}$-derived scaffolds. (m) The molecular weight markers. (A) 3 days, (B) 6 days, and (C) 18 days. The concentration of the separating gel: (A) $10 \%$, (B) $12 \%$, (C) $15 \%$.

line domains gradually increased with time; in contrast, the amino acids with large side chains and polar groups, such as Asp, Thr, Glu, Tyr, Phe, His, Arg and Pro, gradually decreased with time (Tables 2 and 3). This result was consistent with the FTIR analysis, indicating that the amorphous regions of SF were preferentially degraded.
The amino acid changes observed for the $\mathrm{Ca}\left(\mathrm{NO}_{3}\right)_{2}$-derived scaffolds were similar to the changes observed for the LiBr-derived scaffolds (data not shown); additionally, the amino acids composition of the residual $\mathrm{CaCl}_{2}$-derived scaffold at 18 days was not examined because the degradation remains were too little to collect. The scaffolds were degraded into polypeptides and free amino acids. The content of free amino acids released from the $\mathrm{CaCl}_{2}$-derived scaffolds was $854.5 \mu \mathrm{g} / \mathrm{mL}$ after 6 days of degradation, which was significantly higher than the value of $499.9 \mu \mathrm{g} / \mathrm{mL}$ obtained for the LiBr-derived scaffolds (Tables 2 and 3). This result was consistent with the mass loss examination, indicating that the $\mathrm{CaCl}_{2}$-derived scaffolds were more readily degraded by Collagenase IA.

\subsection{In Vivo Degradation Assessment}

To study the relationship between the in vivo degradation and MW, the SF scaffolds were implanted into full-thickness wounds of the dermis tissue in SD rats for 28 days. Figure 6 shows the H \& E staining images of 
Table 3. The amino acid compositions of the degradation remains and the free amino acid contents of the degradation products from the $\mathrm{CaCl}_{2}$-derived scaffold. ND* : Not determined.

\begin{tabular}{|c|c|c|c|c|}
\hline \multirow{2}{*}{ Amino acids } & \multicolumn{2}{|c|}{ Amino acid compositions of the remains ( $\mathrm{mol} \%$ ) } & \multicolumn{2}{|c|}{ Free amino acid contents of the degradation products $(\mu \mathrm{g} / \mathrm{mL})$} \\
\hline & 0 day & 6 days & 6 days & 18 days \\
\hline Asp & $1.66 \pm 0.00$ & $1.53 \pm 0.00$ & $1.50 \pm 0.06$ & $\mathrm{ND}^{*}$ \\
\hline Thr & $0.91 \pm 0.00$ & $0.86 \pm 0.01$ & $5.55 \pm 0.64$ & $3.15 \pm 0.50$ \\
\hline Ser & $10.61 \pm 0.01$ & $10.60 \pm 0.00$ & $4.50 \pm 1.91$ & $3.85 \pm 0.07$ \\
\hline Glu & $1.57 \pm 0.01$ & $1.46 \pm 0.01$ & $5.60 \pm 7.92$ & $14.40 \pm 0.85$ \\
\hline Gly & $43.42 \pm 0.01$ & $43.87 \pm 0.02$ & $366.95 \pm 0.07$ & $\mathrm{ND}^{*}$ \\
\hline Ala & $30.17 \pm 0.06$ & $30.45 \pm 0.03$ & $72.70 \pm 0.28$ & $\mathrm{ND}^{*}$ \\
\hline Cys & $0.01 \pm 0.00$ & $0.01 \pm 0.00$ & $\mathrm{ND}^{*}$ & $\mathrm{ND}^{*}$ \\
\hline Val & $1.87 \pm 0.00$ & $1.81 \pm 0.00$ & $\mathrm{ND}^{*}$ & $\mathrm{ND}^{*}$ \\
\hline Ile & $0.56 \pm 0.00$ & $0.52 \pm 0.01$ & $\mathrm{ND}^{*}$ & $\mathrm{ND}^{*}$ \\
\hline Leu & $0.36 \pm 0.01$ & $0.29 \pm 0.00$ & $\mathrm{ND}^{*}$ & $\mathrm{ND}^{*}$ \\
\hline Tyr & $4.71 \pm 0.01$ & $4.68 \pm 0.01$ & $87.90 \pm 0.42$ & $13.60 \pm 0.56$ \\
\hline Phe & $0.69 \pm 0.01$ & $0.64 \pm 0.01$ & $15.05 \pm 0.20$ & $9.45 \pm 0.64$ \\
\hline Lys & $0.21 \pm 0.00$ & $0.21 \pm 0.00$ & $0.45 \pm 0.04$ & $\mathrm{ND}^{*}$ \\
\hline $\mathrm{NH}_{3}$ & $2.42 \pm 0.00$ & $2.31 \pm 0.00$ & $295.85 \pm 3.04$ & $288.95 \pm 0.21$ \\
\hline His & $0.19 \pm 0.00$ & $0.17 \pm 0.01$ & $\mathrm{ND}^{*}$ & $\mathrm{ND}^{*}$ \\
\hline Arg & $0.48 \pm 0.01$ & $0.41 \pm 0.01$ & $\mathrm{ND}^{*}$ & $\mathrm{ND}^{*}$ \\
\hline Pro & $0.17 \pm 0.01$ & $0.16 \pm 0.00$ & $\mathrm{ND}^{*}$ & $\mathrm{ND}^{*}$ \\
\hline Total & 100.01 & 100.03 & $854.50 \pm 9.90$ & $333.40 \pm 0.71$ \\
\hline
\end{tabular}

SF scaffolds in which the most of each scaffolds has been degraded, and new tissue has grown into the inside of the scaffolds. The new tissue formation in the $\mathrm{CaCl}_{2}-$ derived scaffolds was more obvious and better approximated normal dermis tissue. The degradation rate was calculated using a SigmaScan Pro 5.0. The degradation percentage of the $\mathrm{CaCl}_{2}$-derived scaffolds was $83.8 \%$, which was higher than the value of $66.2 \%$ obtained for the LiBr-derived scaffolds; additionally, the degradation rate of the $\mathrm{Ca}\left(\mathrm{NO}_{3}\right)_{2}$-derived scaffolds was slightly higher than for the $\mathrm{LiBr}$-derived scaffolds.

\section{DISSCUSSION}

The degradation rate of SF scaffolds is not only related to the pore structure and crystalline structure but also to the MW level of the SF. After dissolving natural silk fibers to obtain regenerated SF solutions, we can further prepare the biomaterials with the desired configuration, structure and function in an aqueous solution. Example configurations include 3D scaffolds, gels, particles and nanofibers. Many ionic liquids, such as $\mathrm{Ca}\left(\mathrm{NO}_{3}\right)_{2}, \mathrm{LiBr}$, $\mathrm{Ca}\left(\mathrm{NO}_{3}\right)_{2} /$ methanol $/ \mathrm{H}_{2} \mathrm{O}, \mathrm{CaCl}_{2} / \mathrm{EtOH} / \mathrm{H}_{2} \mathrm{O}$ and $\mathrm{LiSCN}$,
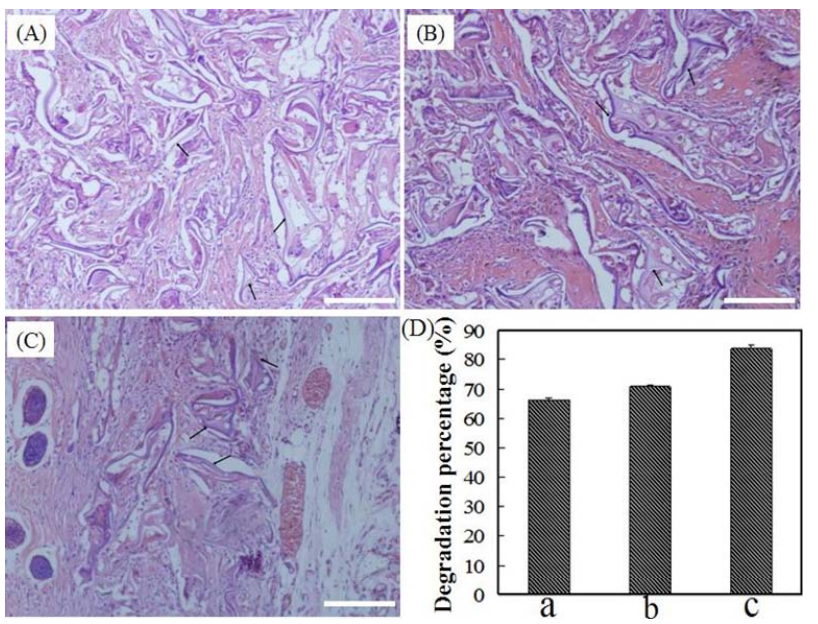

Figure 6. (A)-(C): $\mathrm{H} \& \mathrm{E}$ stains of the SF scaffolds after subcutaneous implantation in rats for 28 days for (A) the LiBr-derived scaffold; (B) the $\mathrm{Ca}\left(\mathrm{NO}_{3}\right)_{2}$-derived scaffold; and (C) the $\mathrm{CaCl}_{2}$-derived scaffold. The black arrows mark the undegraded scaffolds. Scale bars $=100 \mu \mathrm{m}$; (D) The degradation percentages of the SF scaffolds for (a) The LiBr-derived scaffolds; (b) The $\mathrm{Ca}\left(\mathrm{NO}_{3}\right)_{2}$-derived scaffolds; and (c) The $\mathrm{CaCl}_{2}$-derived scaffolds. 
have been successfully used to dissolve silk fibers [4-6, 24-26]. In this study, we investigated the effects of three ionic liquid solvents, $\mathrm{LiBr}, \mathrm{Ca}\left(\mathrm{NO}_{3}\right)_{2}$ and $\mathrm{CaCl}_{2} / \mathrm{EtOH} /$ $\mathrm{H}_{2} \mathrm{O}$, on the MW level of regenerated SF. We regulated the degradation rate of the $3 \mathrm{D}$ scaffolds by changing the MW level.

Although the MWD of the SF derived from all three solvents ranged from 20 to $300 \mathrm{kDa}$, the LiBr-derived SF solution contained more high-MW SF. In contrast, the SF solution produced by $\mathrm{CaCl}_{2}$ contained more abundant low-MW polypeptides, indicating that $\mathrm{CaCl}_{2}$ has a stronger dissolution effect on silk fibroin fibers than either $\mathrm{LiBr}$ or $\mathrm{Ca}\left(\mathrm{NO}_{3}\right)_{2}$. Recently, Um et al. [27] used gel permeation chromatography (GPC) combined with fast protein liquid chromatography (FPLC) to compare the MWs and MW distributions of the regenerated SF prepared by $\mathrm{LiBr}$ and $\mathrm{CaCl}_{2} / \mathrm{CH}_{3} \mathrm{CH}_{2} \mathrm{OH} / \mathrm{H}_{2} \mathrm{O}$; they found that the SF produced by LiBr had a higher MW level, which was consistent with our observations. The results obtained by Phillips et al. [18] demonstrated that the solubility of SF in ionic liquids depends on the identities of both the cation and anion, with the anion having a significantly stronger effect; additionally, the solubility of the SF increases with increasing the ability of the ions to participate in hydrogen bonding. BMIM $\mathrm{Cl}$ can produce a SF solution of up to $13.2 \%(\mathrm{w} / \mathrm{w})$, which is a slightly higher result than in DMBIM $\mathrm{Cl}$. Both BMIM Br and BMIM I dissolve sericin but not fibroin, while neither sericin and fibroin will dissolve in BMIM $\mathrm{BF}_{4}$. Moreover, wideangle X-ray scattering (WAXS) confirmed that the BMIM $\mathrm{Cl}$ disrupted the hydrogen bonds in the crystalline domains of the cocoon silk. These results indicate that small hydrogen-bond acceptors $\left(\mathrm{Cl}^{-}\right)$impart more significant damage to the $\beta$-sheet crystals than either noncoordinating anions or larger anions, including $\mathrm{Br}^{-}$and $\mathrm{I}^{-}$. Therefore, the ability of $\mathrm{CaCl}_{2}$ to disrupt hydrogen bonding makes it an effective solvent for SF; additionally, the stronger ability of $\mathrm{Cl}^{-}$to impart damage to the $\beta$-sheet crystal causes more significant hydrolysis than $\mathrm{NO}_{3}^{-}$ and $\mathrm{Br}^{-}$. Moreover, a high concentration of metal ions can form coordination bonds with the carbonyl oxygen atoms of $\mathrm{SF}$, thereby disrupting the hydrogen bonding within the $\beta$-sheet structure [24-25,28]. The coordination ability of $\mathrm{Li}^{+}$is weaker than the coordination ability of divalent $\mathrm{Ca}^{2+}$, resulting in the mild dissolution of SF in LiBr solution.

The linear fit result of the in vitro degradation data indicates that the mass loss of the SF scaffolds was linearly dependent on the degradation time. The SDS-PAGE and amino acid analysis showed that the SF scaffolds were initially degraded by Collagenase IA into free amino acids and polypeptides at $10-30 \mathrm{kDa}$. The $\mathrm{CaCl}_{2}$-derived scaffolds exhibited the most rapid degradation rate, and the degradation rate of the $\mathrm{Ca}\left(\mathrm{NO}_{3}\right)_{2}$-derived scaf- folds was slightly faster than the degradation of the LiBrderived scaffolds. This result is consistent with our SEM observations, demonstrating that the degradation rate of SF scaffolds is dependent on the low-MW polypeptide content. According to the fringed fibril model [29], longchain SF macromolecules pass through many small crystallites and amorphous regions in the fringed aggregation structure, in which micro-aggregations are connected by a significant number of molecular chains. As the initial MW of the SF scaffolds increases, the SF macromolecules are able to pass through more small crystallites, and the inter-intramolecular entanglement also increases. In our $\mathrm{CaCl}_{2}$-derived scaffolds containing a significant quantity of low-MW SF, the micro-aggregations were readily disassembled after enzymatic attack, and the lowMW polypeptides were rapidly released from the scaffolds due to the decreased inter-intramolecular entanglement, which resulted in a increased degradation rate. The results of the SDS-PAGE and amino acid analysis showed that the amino acid and polypeptide (10 - $30 \mathrm{kDa})$ contents released from the $\mathrm{CaCl}_{2}$-derived scaffolds were significantly higher than for either the $\mathrm{LiBr}$-derived scaffolds or the $\mathrm{Ca}\left(\mathrm{NO}_{3}\right)_{2}$-derived scaffolds, demonstrating that the decreased SF MW level enhanced the release rate of the amino acids and polypeptides.

The FTIR analysis indicates that the amorphous regions were preferentially degraded by Collagenase IA, resulting in the increased $\beta$-sheet content and decreased random coil structure content. Clostridium histolyticum collagenase IA degrades the amino acid combination -Xaa-Gly- very easily [30]. The high -Xaa-Gly- content in the non- $\beta$-sheet region of SF may be an important contributor to the rapid degradation of the amorphous regions. The SF crystalline domains consist of abundant GAGAGS, GAGAGY, GAGAGA or GAGYGA, where $\mathrm{G}$ is glycine, $\mathrm{A}$ is alanine, $\mathrm{S}$ is serine and $\mathrm{Y}$ is tyrosine [22]. The amino acids with large side chains and polar groups are mainly present in the amorphous regions [31-32]. The relative Gly, Ala and Ser contents increased after degradation, while the levels of Asp, Thr, Glu, His, Arg, Phe and Pro, all of which contain large side chains and polar groups, decreased (Tables 2 and 3). This result indicates the preferential degradation of the amorphous regions, further confirming the results obtained by FTIR.

The extracellular matrixes of dermis and bone tissues, among others, contain abundant Collagen I and Collagenase I. In our study, the SF 3D scaffolds were implanted into full-thickness wounds in the dermis tissue in the backs of SD rats to investigate their in vivo degradation behavior. After 28 days, scaffold degradation was readily apparent, and regenerated tissue had formed. The degradation rate of the $\mathrm{CaCl}_{2}$-derived scaffolds reached a value of $83.8 \%$, which was significantly higher than the degradation of the $\mathrm{LiBr}$ and $\mathrm{Ca}\left(\mathrm{NO}_{3}\right)_{2}$-derived scaffolds; 
this result was consistent with the in vitro degradation results. $\mathrm{H} \& \mathrm{E}$ staining showed that larger quantities of new tissue formed in the $\mathrm{CaCl}_{2}$-derived scaffolds, indicating that the degradation rate of the $\mathrm{CaCl}_{2}$-derived scaffolds was better matched with the regeneration rate of the dermis tissue. The results of both the in vitro and the in vivo degradation experiments suggest that changing the MW of the SF is an efficient approach for regulating the degradation rate of $3 \mathrm{D}$ scaffolds to meet various tissue regeneration rate requirements.

\section{CONCLUSION}

Both the in vitro degradation model of Collagenase IA from Clostridium histolyticum and the in vivo experiment with full-thickness wounds showed distinct degradation differences in the SF scaffolds derived from the different solvents. $\mathrm{CaCl}_{2}$-derived $\mathrm{SF}$ has a lower $\mathrm{MW}$ level in comparison to the regeneration process of $\mathrm{LiBr}$ and $\mathrm{Ca}\left(\mathrm{NO}_{3}\right)_{2}$, resulting in a rapid degradation rate. The results of the SDS-PAGE and amino acid analysis suggested that the SF scaffolds were degraded into polypeptides and free amino acids. The FTIR and amino acid analysis indicated that Collagenase IA preferentially attacked the amorphous regions of SF. The in vivo experiments indicated that the $\mathrm{CaCl}_{2}$-derived scaffold was suited for the regeneration of dermis tissue due to its more rapid degradation rate. These results can significantly contribute to the regulation of the degradation rate of SF materials in the future to meet various tissue repair requirements.

\section{REFERENCES}

[1] Drury, J.L. and Mooney, D.L. (2003) Hydrogels for tissue engineering: Scaffold design variables and applications. Biomaterials, 24, 4337-4351. doi:10.1016/S0142-9612(03)00340-5

[2] Mandal, B.B., Grinberg, A., Gil, E.S., Panilaitis, B. and Kaplan, D.L. (2012) High-strength silk protein scaffolds for bone repair. Proceedings of the National Academy of Sciences of the United States of America, 109, 7699-7704. doi:10.1073/pnas.1119474109

[3] Marelli, B., Alessandrino, A., Farè, S., Freddi, G., Mantovani, D. and Tanzi, M.C. (2010) Compliant electrospun silk fibroin tubes for small vessel bypass grafting. Acta Biomaterialia, 6, 4019-4026. doi:10.1016/j.actbio.2010.05.008

[4] Zhang, Q., et al. (2012) Preparation of uniaxial multichannel silk fibroin scaffolds for guiding primary neurons. Acta Biomaterialia, 8, 2628-2638. doi:10.1016/j.actbio.2012.03.033

[5] Foss, C., Merzari, E., Migliaresi, C. and Motta, A. (2013) Silk fibroin/hyaluronic acid 3D matrices for cartilage tissue engineering. Biomacromolecules, 14, 38-47. doi:10.1021/bm301174x
[6] Mandal, B.B., Park, S-H., Gil, E.S. and Kaplan, D.L. (2011) Multilayered silk scaffolds for meniscus tissue engineering. Biomaterials, 32, 639-651. doi:10.1016/j.biomaterials.2010.08.115

[7] Li, M., Ogisob, M. and Minoura, N. (2003) Enzymatic degradation behavior of porous silk fibroin sheets. Biomaterials, 24, 357-365. doi:10.1016/S0142-9612(02)00326-5

[8] Horan, R.L., et al. (2005) In vitro degradation of silk fibroin. Biomaterials, 26, 3385-3393. doi:10.1016/j.biomaterials.2004.09.020

[9] Hu, Y., Zhang, Q., You, R., Wang, L. and Li, M. (2012) The relationship between secondary structure and biodegradation behavior of silk fibroin scaffolds. Advances in Materials Science and Engineering, 2012, Article ID: 185905.

[10] Arai, T., Freddi, G., Innocenti, R. and Tsukada, M. (2004) Biodegradation of Bombyx mori silk fibroin fibers and films. Journal of Applied Polymer Science, 91, 23832390. doi:10.1002/app.13393

[11] Zhao, C., Wu, X., Zhang, Q., Yan, S. and Li, M. (2011) Enzymatic degradation of Antheraea pernyi silk fibroin $3 \mathrm{D}$ scaffolds and fibers. International Journal of Biological Macromolecules, 48, 249-255. doi:10.1016/j.ijbiomac.2010.11.004

[12] Wang Y., et al. (2008) In vivo degradation of three-dimensional silk fibroin scaffolds. Biomaterials, 29, 3415-3428. doi:10.1016/j.biomaterials.2008.05.002

[13] Zhou, J., Cao, C., Ma, X., Hu, L., Chen, L. and Wang C. (2010) In vitro and in vivo degradation behavior of aqueous-derived electrospun silk fibroin scaffolds. Polymer Degradation and Stability, 95, 1679-1685. doi:10.1016/j.polymdegradstab.2010.05.025

[14] Yang, Y., et al. (2009) Degradation behaviors of nerve guidance conduits made up of silk fibroin in vitro and in vivo. Polymer Degradation and Stability, 94, 2213-2220. doi:10.1016/j.polymdegradstab.2009.09.002

[15] Numata, K., Cebe, P. and Kaplan, D.L. (2010) Mechanism of enzymatic degradation of beta-sheet crystals. Biomaterials, 31, 2926-2933. doi:10.1016/j.biomaterials.2009.12.026

[16] Kim, K., et al. (2003) Control of degradation rate and hydrophilicity in electrospun non-woven poly(d,1-lactide) nanofiber scaffolds for biomedical applications. Biomaterials, 24, 4977-4985. doi:10.1016/S0142-9612(03)00407-1

[17] Park, T.G. (1994) Degradation of poly(d,1-lacticacid) microspheres: Effect of molecular weight. Journal of Controlled Release, 30, 161-173. doi:10.1016/0168-3659(94)90263-1

[18] Phillips, D.M., et al. (2004) Dissolution and regeneration of Bombyx mori silk fibroin using ionic liquids. Journal of the American Chemical Society, 126, 14350-14351. doi:10.1021/ja046079f

[19] Hu, X., Kaplan, D and Cebe, P. (2006) Determining betasheet crystallinity in fibrous proteins by thermal analysis and infrared spectroscopy. Macromolecules, 39, 61616170. doi: $10.1021 / \mathrm{ma} 0610109$ 
[20] Yan, S., et al. (2013) Silk fibroin/chondroitin sulfate/ hyaluronic acid ternary scaffolds for dermal tissue reconstruction. Acta Biomaterialia, 9, 6771-6782. doi:10.1016/j.actbio.2013.02.016

[21] Vepari, C. and Kaplan, D.L. (2007) Silk as a biomaterial. Progress in Polymer Science, 32, 991-1007. doi:10.1016/j.progpolymsci.2007.05.013

[22] Zhou, C.Z., Confalonieri, F., Jacquet, M., Perasso, R., Li, Z.G. and Janin, J. (2001) Silk fibroin: Structural implications of a remarkable amino acid sequence. Proteins: Structure, Function, and Bioinformatics, 44, 119-122.

[23] Inoue, S., Tanaka, K., Arisaka, F., Kimura, S., Ohtomo, K. and Mizuno, S. (2000) Silk fibroin of Bombyx mori is secreted, assembling a high molecular mass elementary unit consisting of H-chain, L-chain, and P25, with a 6:6:1 molar ratio. The Journal of Biological Chemistry, 275, 40517-40528. doi:10.1074/jbc.M006897200

[24] Mathur, A.B., Tonelli, A., Rathke, T. and Hudson, S. (1997) The dissolution and characterization of Bombyx mori silk fibroin in calcium nitrate-methanol solution and the regeneration of films. Biopolymers, 42, 61-74. doi:10.1002/(SICI)1097-0282(199707)42:1<61::AID-BIP 6>3.0.CO;2-\#

[25] Ha, S.-W., Park, Y.H. and Hudson, S.M. (2003) Dissolution of bombyx mori silk fibroin in the calcium nitrate tetrahydrate-methanol system and aspects of wet spinning of fibroin solution. Biomacromolecules, 4, 488-496. doi:10.1021/bm0255948

[26] Yamada, H., Nakao, H., Takasu., H, Takasu, Y. and Tsub- ouchi, K. (2001) Preparation of undegraded native molecular fibroin solution from silkworm cocoons. Materials Science and Engineering: C, 14, 41-46. doi:10.1016/S0928-4931(01)00207-7

[27] Cho, H.J., Ki, C.S., Oh, H., Lee, K.H. and Um, I.C. (2012) Molecular weight distribution and solution properties of silk fibroins with different dissolution conditions. International Journal of Biological Macromolecules, 51, 336341. doi:10.1016/i.ijbiomac.2012.06.007

[28] Yan, S.Q., Zhao, C.X., Wu, X.F., Zhang, Q. and Li, M.Z. (2010) Gelation behavior of Antheraea pernyi silk fibroin. Science China Chemistry, 53, 535-541. doi:10.1007/s11426-010-0093-0

[29] Hearle, J.W.S. (1958) A fringed fibril theory of structure in crystalline polymers. Journal of Polymer Science, 28, 432-435. doi:10.1002/pol.1958.1202811722

[30] Seifter, S. and Harper, E. (1971) The enzymes. 3rd Edition, In: Boyer, P., Ed., Academic Press Inc., New York, 649.

[31] Katagata, Y., Kikuchi, A. and Shimura K. (1984) Characterization of the crystalline-region peptides prepared from the posterior silk gland fibroin. Journal of Sericultural Science of Japan, 53, 165-174.

[32] Katagata, Y., Kikuchi, A. and Shimura, K. (1984) Fractionation and characterization of the amorphous-region peptides of fibroin prepared from the posterior silk gland. Journal of Sericultural Science of Japan, 53, 226-236. 